\title{
Autoregulation in Infants with Neonatal Encephalopathy
}

\author{
Andrea C. Pardo, $\mathrm{MD}^{1 *}$ \\ ${ }^{I}$ Division of Neurology, Ann \& Robert H. Lurie Children's Hospital of Chicago, Chicago, IL; and \\ Departments of Pediatrics and Neurology, Northwestern University Feinberg School of Medicine, Chicago, IL \\ *Correspondence: Dr. Andrea C. Pardo, E-mail: apardo@luriechildrens.org
}

Related Article: Burton VJ, Gerner G, Cristofalo E, Chung SE, Jennings JM, Parkinson C et al. A pilot cohort study of cerebral autoregulation and 2-year neurodevelopmental outcomes in neonates with hypoxic-ischemic encephalopathy who received therapeutic hypothermia. BMC Neurol 2015;15(1):209.

Keywords: Hypoxic Ischemic Encephalopathy; Therapeutic Hypothermia; Autoregulation

Researchers from Johns Hopkins School of Medicine report a pilot observational study investigating the influence of hemodynamic management in 28 neonates with hypoxic ischemic injury (HIE). This cohort of neonates, all of whom underwent therapeutic hypothermia, were evaluated with Near Infrared Spectroscopy (NIRS) to obtain the hemoglobin volume index (HVx) as a marker of cerebral autoregulation that identifies the optimal mean arterial blood pressure (MAPOPT) at which optimal autoregulation is achieved. The investigators identified the MAPOPT for 3 time periods: hypothermia, rewarming and first 6 hours of normothermia. They compared the effect of MAPOPT on neurodevelopmental outcomes at 2 years. A total of 19 patients remained in the study after follow up. Within the cohort of 19 patients, only 15 patients underwent the full research battery of standardized cognitive and motor scales. Neurodevelopmental outcomes were classified as impaired or unimpaired. In this cohort, $42 \%$ of the children were identified as having impaired cognitive or motor function. The investigators only found differences in outcome when they compared the MAPOPT during the rewarming period. The investigators found that children with an impaired outcome had higher MAPOPT $(\mathrm{p}=0.023)$, and spent a greater percentage of time during rewarming with blood pressures under their identified MAPOTP $(p=0.048)$. The authors suggest that monitoring and management of HVx as a marker of autoregulation may have an impact on neurodevelopmental outcomes of neonates affected by HIE. [1]

COMMENTARY. HIE in the neonate remains a public health concern. Therapeutic hypothermia is currently the standard of care for neonates with moderate to severe HIE, and although it has decreased death and disability, adverse neurodevelopmental outcomes are still prevalent [2]. The mechanisms of cerebral perfusion patterns in neonates are not well understood [3]. Understanding patterns of cerebral blood flow and autoregulation is paramount to establish therapies directed at maintaining adequate cerebral perfusion and avoid reperfusion injury. Although NIRS monitoring does not provide a direct prognostic utility in the management of infants with HIE undergoing hypothermia [4], it may provide a putative value for autoregulation and optimal blood pressures goals, and guide management to achieve adequate cerebral perfusion in the neonate.

This study highlights the need for closer hemodynamic monitoring aimed at maintaining optimal cerebral autoregulation in neonates undergoing therapeutic hypothermia as this may impact neurodevelopmental outcomes.

\section{Disclosures}

The author(s) have declared that no competing interests exist.

\section{References}

1. Burton VJ, Gerner G, Cristofalo E, Chung SE, Jennings JM, Parkinson $\mathrm{C}$ et al. A pilot cohort study of cerebral autoregulation and 2-year neurodevelopmental outcomes in neonates with hypoxic-ischemic encephalopathy who received therapeutic hypothermia. BMC Neurol 2015;15(1):209. http://dx.doi.org/10.1186/s12883-015-0464-4 PMID: 26486728

2. Shankaran S, Barnes PD, Hintz SR, Laptook AR, Zaterka-Baxter KM, McDonald SA et al.; Eunice Kennedy Shriver National Institute of Child Health and Human Development Neonatal Research Network. Brain injury following trial of hypothermia for neonatal hypoxic-ischaemic encephalopathy. Arch Dis Child Fetal Neonatal Ed 2012 Nov;97(6):F398-F404. http://dx.doi.org/10.1136/archdischild-2011301524 PMID:23080477

3. Massaro AN, Bouyssi-Kobar M, Chang T, Vezina LG, du Plessis AJ, Limperopoulos C. Brain perfusion in encephalopathic newborns after therapeutic hypothermia. AJNR Am J Neuroradiol 2013 Aug;34(8):1649-1655. http://dx.doi.org/10.3174/ajnr.A3422 PMID: 23493898

4. Shellhaas RA, Thelen BJ, Bapuraj JR, Burns JW, Swenson AW, Christensen MK et al. Limited short-term prognostic utility of cerebral NIRS during neonatal therapeutic hypothermia. Neurology 2013 Jul;81(3):249-

255. http://dx.doi.org/10.1212/WNL.0b013e31829bfe41 PMID:2377148 3

Pediatric Neurology Briefs 2015;29(10):75. http://dx.doi.org/10.15844/pedneurbriefs-29-10-2

ISSN: 1043-3155 (print) 2166-6482 (online). Received 2015 Oct 29. Accepted 2015 Nov 7. Published 2015 Nov 17.

(c) BY (C2015 The Author(s). This work is licensed under a Creative Commons Attribution 4.0 International License. 